\title{
Narrativas em diários online: uma pesquisa formação no Programa Institucional de Bolsa de Iniciação à Docência do Curso de Pedagogia
}

\author{
Socorro Aparecida Cabral Pereira (UESBi) \\ Simone Lucena (UFS)
}

\section{Resumo}

O texto discute sobre a importância das narrativas como estratégia formativa dos bolsistas do Programa de Bolsas de Iniciação à Docência, destacando esse espaço multireferrencial de reflexões sobre a prática docente nas escolas, bem como lócus de colaboração vivenciado pelos pares. A partir da experiência empírica com os bolsistas, identificamos o diário online como uma interface potencializadora para o exercício da escrita, a reflexão, e a socialização de dilemas docentes. A metodologia utilizada foi a pesquisa-formação na cibercultura, por possibilitar aos sujeitos aprendentes um olhar sobre si mesmos ao longo de suas vidas, em que a narrativa é destaque, pois ela permitiu aos sujeitos explicitarem a singularidade e perceber o caráter processual da formação e da vida, articulando espaços, tempos e as diferentes dimensões de nós mesmos e no empoderamento do sujeito social contemporâneo.

Palavras-chave: Diários online. Iniciação à Docência. Educação.

\section{Narratives in online journals: a research training in the Institutional Program of Purchase Board of Teaching Course of the Pedagogy Course}

\section{Abstract \\ This text discusses the importance of the students' narratives from the Initiation Teaching Scholarships Programs as a formative strategy, empha-}


sizing this multi-referential space of reflections about the teaching practicing in schools, as well as the collaborative locus lived by the pairs. From the practical experience with the scholarships students, it was possible to identify the online diary as a potential interface to the exercise of writing, reflection, the socialization of the teaching dilemmas. The methodology used in this research was the research training in the cyberculture, by enabling the learning subjects a view about themselves along their journeys where the narrative is an emphasis, since it enabled the subjects to clarify the singularity e realize the processual aspect of the life's formation, articulating spaces, times and the different dimensions of ourselves, during the empowerment of the social contemporary subject.

Keywords: Education. Online Diaries. Teaching Initiation.

\section{Narrativas en diarios online: una investigación formación en el Programa Institucional de Bolsa de Iniciación a la Docencia del Curso de Pedagogía}

\section{Resumen}

Este texto discute la importancia de las narrativas de los estudiantes de los Programas de Becas de Iniciación para la Enseñanza como una estrategia formativa, enfatizando este espacio de reflexiones multi-referenciales sobre la práctica docente en las escuelas, así como el locus de colaboración vivido por las parejas. A partir de la experiencia práctica con los estudiantes de becas, fue posible identificar el diario en línea como una posible interfaz para el ejercicio de la escritura, la reflexión, la socialización de los dilemas de la enseñanza. La metodología utilizada en esta investigación fue la formación en investigación en cibercultura, al permitir a los sujetos de aprendizaje una visión de sí mismos a lo largo de sus trayectos donde la narración es un énfasis, ya que permitió a los sujetos clarificar la singularidad y realizar el aspecto procesual de la vida. formación, articulación de espacios, tiempos y las diferentes dimensiones de nosotros mismos, durante el empoderamiento del sujeto social contemporáneo.

Palabras Clave: Diarios en línea. Educación. Iniciación a la docência.

\section{Introdução}

O desenvolvimento tecnológico do atual século XXI tem possibilitado o acesso ao ciberespaço por diferentes dispositivos. 
O que denominamos de tecnologias digitais em rede ou de "tecnologias nômades de comunicação" (Silva, 2013) são os dispositivos móveis como smartphones, tablets e personal digital assistants (PDA) que "criam comunidades não contíguas em espaços físicos (...) reinventam espaços urbanos como ambientes de multiusuários" (SILVA, 2013, p. 283). Estas tecnologias potencializam que pessoas distantes fisicamente possam se comunicar em espaços híbridos, conectados por meio de rede móvel, ao mesmo tempo em que se deslocam pelo espaço físico habitado por outros praticantes culturais (CERTEAU, 2011) com quem muitas vezes também interagem simultaneamente. Para Santos, Maddalena e Rossini (2006, p. 23) "o dispositivo móvel quando se conecta no espaço virtual híbrido entre o ciberespaço e a cidade emergem novas possibilidades de usos e práticas sociais".

As tecnologias digitais móveis ao serem conectadas a redes sem fio como $W i$-fi, $W i$-max, peer-to-peer, bluetooth possibilitam que os praticantes culturais tenham dupla mobilidade e possam habitar diferentes espaçostempos ${ }^{1}$ multirreferenciais redimencionando assim os espaços urbanos. Entretanto, vale ressaltar, que a mobilidade não é um fenômeno inaugurado pelas das tecnologias móveis, pois desde o início da civilização os seres humanos eram nômades e por isso vivam em mobilidade física, Lemos (2009) apontam além da mobilidade física outras formas de mobilidade a informacional-virtual, que faz circular as informações em rede. O que as redes sem fim conectadas aos dispositivos móveis estão possibilitando hoje é o que a Santaella (2010) chama de espaços interstíciais constituídos pela ubiquidade e conectividade. Os espaços intersticiais são uma intersecção entre o espaço físico e o ciberespaço. Isso ocorre, por exemplo, quando trocamos mensagens com outra pessoa que está

Optamos por esta forma outra de escrita, com base em Alves (2015) que propõe uma escrita com força política que intenciona superar as dicotomias e fragmentações da ciência moderna. Assim assumimos aqui a grafia de palavras juntas que representam uma postura de pensarfazer com/no cotidiano ações que não se separam. 
fisicamente distante por meio de aplicativos usando o telefone celular e ao mesmo tempo continuamos a fazer a atividade no local presencial em que no encontramos.

O que torna possível coincidir o deslocamento físico com a comunicação é a ubiquidade, porém é preciso esclarecer que ela não é sinônimo de mobilidade. A ubiquidade pode ser entendida, de acordo com Santaella (2010), como a possibilidade compartilhamento de diversos espaçostempos simultaneamente. $\mathrm{Na}$ comunicação móvel ela ocorre "quando a continuidade temporal do vínculo comunicacional é assimilada a uma plurilocalização instantânea" (SANTAELLA, 2010, p. 18). Desta forma, podemos compreender a ubiquidade como forma de comunicação a qualquer hora, o tempo todo, por meio dos dispositivos móveis acessados em qualquer lugar.

No campo educacional e na formação inicial de professores, os dispositivos móveis em rede possibilitam outras práticas pedagógicas que privilegiam a produção colaborativa de saberesfazeres que utilizam a cultura e a cidade como espaçostempos de aprendizagem. Com os smartphones é possível realizar os registros nos diários online utilizando textos, vídeos, áudios ou fotografias das situações de aprendizagem no momento em que elas estão acontecendo.

A produção de diários de pesquisa é uma prática utilizada há bastante tempo por muitos pesquisadores em diferentes áreas do conhecimento. Para Barbosa e Hess (2010) ou diário de pesquisa é um instrumento impar que possibilita a escrita com sentido para uma aprendizagem implicada, pois "trata-se da busca de sentido para aquilo que se aprende" (BARBOSA e HESS, 2010, p. 25). Portanto é uma forma de ser, de se colocar com sentido e significado. $\mathrm{Na}$ contemporaneidade as tecnologias digitais móveis presentes no cotidiano de docentes e discentes possibilita a produção do diário de pesquisa em mobilidade e ubiqüidade.

De acordo da pesquisa TIC em Domicílio 2016 desenvolvida pelo Comitê Gestor da Internet (Cetic.br) 86\% dos brasileiros acessam a rede internet por meio de conexão Wi-fi e 70\% utilizam conexão de rede $3 \mathrm{G}$ ou $4 \mathrm{G}$ no telefone celular. Outro importante 
desta pesquisa é que uma em cada quatro pessoas utilizam a internet exclusivamente por meio de Wi-fi, prática geralmente realizada entre $42 \%$ dos jovens entre 10 e 15 anos. Ou seja, a faixa etária dos alunos que estão na escola utilizando as redes e aprendendo em mobilidade e ubiquidade. E nós professores como preparar os discentes na iniciação à docência para inserirem as tecnologias digitais nas suas práticas pedagógicas? Os diários online podem ser uma interface de reflexão e interação sobre os dilemas docentes?

As respostas para estes questionamentos não parecem fáceis, pois como não alerta Pretto (2017, p. 139) "não sejamos simplistas. O momento atual é complexo, como também o é a vida. [...] É urgente que superemos definitivamente as atuais concepções de educação que forma para a linearidade e não para a complexidade." Pensar de forma complexa nos exige um olhar multirreferencial que nos possibilite compreender as transformações sociotécnicas e culturais vivenciadas pela sociedade contemporânea.

Neste texto, que é parte de uma pesquisa em andamento, objetivamos discutir a importância das narrativas em diários online como estratégia formativa dos bolsistas de iniciação à docência do Programa Institucional de Bolsa de Iniciação à Docência (Pibid) Anos Inicias do Ensino Fundamental da Universidade Estadual do Sudoeste da Bahia (UESB) Campus de Jequié no período de 2014 a 2016. Destacando esse espaço multireferrencial de reflexões sobre a prática docente nas escolas, bem como lócus de debate e a colaboração vivenciado pelos pares nos diários online.

\section{Diarismo online na pesquisa formação no Pibib}

O Programa Institucional de Bolsa de Iniciação à Docência (Pibid) foi lançado pela Comissão de Aperfeiçoamento de Pessoal do Nível Superior (Capes), em 2007, inicialmente para as universidades federais, com o objetivo de incentivar a formação de professores para a educação básica e a elevação da qualidade da educação pública.

A UESB (Universidade Estadual do Sudoeste da Bahia) se inseriu no programa em 2010, com a finalidade de realizar um plano 
de trabalho articulado nas licenciaturas, bem como estreitar os laços entre a formação inicial e continuada nas escolas de educação básica dos diferentes municípios. Esta instituição possui três campi, instalados nos municípios de Vitória da Conquista, Jequié e Itapetinga, oferecendo 47 cursos de graduação, sendo 22 cursos de licenciatura nas áreas de Física, Matemática, Química, Ciências Biológicas, Educação Física, Filosofia, Geografia, História, Letras Vernáculas, Letras Modernas, Pedagogia, Ciências Sociais, Teatro e Dança. São oferecidos também 17 cursos de pós-graduação stricto sensu.

O Pibid na UESB traz como perspectiva de trabalho a criação de uma microrrede de ensino aprendizagem-formação, tendo na interdisciplinaridade o princípio que orienta as ações voltadas à dialogicidade, à integração do conhecimento, na perspectiva de gerar novos questionamentos, visando mudanças na realidade educacional, num constante diálogo entre as disciplinas. O projeto institucional tem também como objetivo proporcionar uma formação capaz de desenvolver atitudes críticas, autônomas, colaborativas, criativas e comprometidas por parte de todos os envolvidos: bolsistas de Iniciação à Docência (ID), professores supervisores e coordenadores de área. (PROJETO INSTITUCIONAL DO PIBID DA UESB, 2014). Para ilustrar melhor as funções descritas acima, construímos um organograma.

Figura 1 - Organograma das funções do Pibid

\section{Organograma das Funções - Pibid}
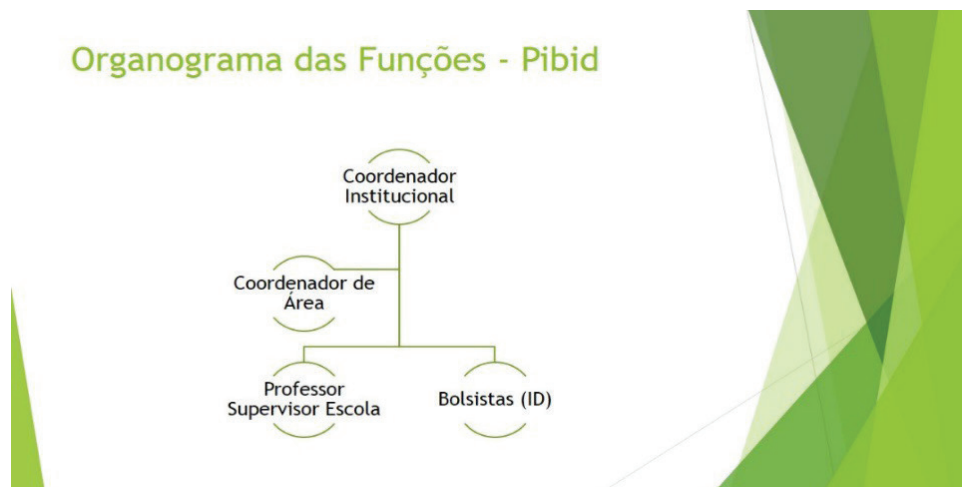

Fonte: Produzido pelas autoras 
Conceber um programa de iniciação à docência, requer de nós a emergência de construir um novo desenho metodológico de desenvolvimento profissional, a partir da retomada dos professores experientes na universidade, no sentido de discutirem suas práticas docentes juntamente com os licenciandos em início de carreira e os professores coordenadores de cada curso, no intuito de construírem novas formas de aprendizagemensino, a partir das carências da escola.

As reuniões de cada subprojeto eram realizadas semanalmente na escola e na universidade, tendo como foco algumas ações do projeto institucional e as especificidades de cada modalidade de ensino, a saber: a pesquisa etnográfica, as rodas de estudo, a monitoria didática, o círculo de investigação, o planejamento e elaboração de materiais didáticos, entre outros. Essas ações visam fortalecer os vínculos entre a Universidade e a Escola de Educação Básica, fomentando a produção de conhecimentos e a formação crítico-reflexiva sobre a docência. Em sintonia com as reuniões realizadas na universidade e na escola, realizamos a formação utilizando o Ambiente Virtual de Aprendizagem Moodle ${ }^{2}$, no site de rede social Facebook ${ }^{3}$ e o $\mathrm{Blog}^{4}$ como diário online, buscando ampliar os espaços formativos do Pibid. A presença das tecnologias digitais, no contexto do subprojeto de Pedagogia, tem nos desafiado a vivenciar processos de aprendizagem bilaterais, em que o sujeito aprende com o outro.

Com o objetivo de implementarmos ações de desenvolvimento profissional pautados numa comunicação bidirecional, em

2 O Moodle, cuja abreviatura modular é “Object - Oriented Dynamic Learning Environment”, surgiu como experiência em 1999, criado por Martin Dougiamas, sob a forma de comunidade virtual.

3 O Facebook surgiu no ano de 2003, sob a concepção de Mark Zuckberg, disponibilizando aos usuários as possibilidades de curtir, comentar e compartilhar.

4 Contração dos termos em inglês web $+\log$, Weblog que significa "diário da rede". Trata-se de site que permite a atualização rápida de postagens (post) ou publicações em ordem cronologicamente inversa. A escrita no blog pode ser hipertextual e com interatividade por meio dos comntários. 
ambientes online, construímos um desenho didático no Moodle da UESB, a partir do entrelaçamento de várias atividades e da disponibilização de diferentes interfaces, visando uma maior reflexão sobre as vivências desencadeadas no curso. Compreendemos por desenho didático as fases de planejamento, execução e utilização dos conteúdos e atividades que buscam organizar a itinerância da aprendendizagemensino em ambientes online, lançando mão de interfaces de conteúdo e de comunicação. Salientamos que nossos bolsistas são alunos oriundos da licenciatura e não dispõem de horários tão flexíveis de tempo integral para todas as atividades propostas no programa. Assim, o Moodle se tornou um espaço fecundo de debates e reflexões, articulado aos encontros presenciais semanais e à imersão na cultura escolar. Ressaltamos que no ambiente Moodle, agregamos a possibilidade de fazer a convergência de mídias, utilizando para isso vídeos, áudios e mídias disponíveis na internet, tais como chats, fóruns, blogs etc. Tudo isso de forma ubíqua e utilizando também as tecnologias digitais móveis.

Dentre as interfaces disponibilizadas no Moodle escolhemos utilizar o diário na perspectiva de "diário de formação" que de acordo com Barbosa e Hess (2010, p. 73) "se propões a registrar o próprio processo formativo vivenciado no decorrer de um curso". No ambiente virtual o diário é uma interface assíncrona geralmente utilizada para que os alunos registrem sua itinerância de aprendizagem, ou mesmo para que possam construir algum texto solicitado na disciplina. Será o desenho didático da formação que definirá a proposta de trabalho mais adequada.

Além do diário no Moodle, outra interface utilizada na pesquisa para a escrita de narrativas na forma de diário foi o blog. A escolha por esta interface se deu pelo fato do diário no blog poder ser lido e comentado por toda a turma, pois no Moodle não há esta possibilidade de interatividade. No blog os bolsistas ID narravam suas experiências vivenciadas na sala de aula da educação básica. Já a escolha por criar um grupo no Facebook, se deu em virtude deste site de rede social poder ser acessado de forma ubí- 
qua por todos os participantes e em diferentes dispositivos móveis como notebooks, smartphones e tablets permitindo trocas mais constates entre todos.

Santos (2004) nos apresenta o conceito do diário como o registro dos acontecimentos do dia a dia, do cotidiano refletido pelo autor. Ao mesmo tempo, traz a evolução desse conceito. Teríamos inicialmente o suporte material restrito ao mundo privado do autor. Assim, a imprensa contribuiu com a distribuição impressa dos mesmos em diferentes espaços. Saltamos do suporte material para o suporte digital, permitindo que o diário fosse compartilhado de forma síncrona e assíncrona, sempre em potência e nem sempre em ato, como ressalta a autora.

Caracterizamos o contexto digital por apresentar um caráter plástico e não linear das informações. Enquanto que, num livro impresso, os parágrafos, as frases, páginas e os capítulos seguem uma ordem estabelecida pelo autor e pela própria configuração física e sequencial do suporte escrito no meio digital, as informações extrapolam a tridimensionalidade, característica da escrita, e apresentamse como uma rede multidimensional de indicadores apontando para novas formulações, a partir das ações do sujeito (PEREIRA, 2008).

Inspirados nesses pressupostos, destacamos a importância de dialogarmos com a abordagem multireferrencial, Macedo (2002), que muito mais do que a justaposição de olhares disciplinares, supõe a capacidade de falar várias linguagens e inteligibilidades sem as confundir. Para ele, é importante destacar que essa abordagem não se refere a práticas de complementariedade, da necessidade de domínio absoluto ou mesmo da aditividade, mas sim da consciência das limitações dos diferentes campos do saber, além da necessidade de um rigor fecundante e da consciência da nossa ignorância.

\section{Procedimentos metodológicos}

Compreender como os bolsistas de iniciação à docência se desenvolvem profissionalmente no início da carreira no movimento da cibercultura, em espaços online de formação requer do pes- 
quisador o rompimento com uma concepção de ciência que relega a uma condição de não verdade toda e qualquer outra forma de conhecimento que não esteja pautada pelo método científico e suas regras metodológicas.

Diante destes desafios, Morin (2003) nos convida a fazer Ciência com Consciência, reatando com a reflexão filosófica, a consciência política, a moral e a ética na construção do conhecimento. Este desafio requer uma compreensão mais complexa da realidade, a desconstrução da visão simplista, a reflexão e discussão das experiências vivenciadas pelos sujeitos envolvidos no processo. Macedo (2004) ressalta que, para pensarmos sobre a complexidade, é preciso esclarecer que esta não elimina a simplicidade; incorpora a dialogicidade, opondo-se radicalmente às antinomias e simplificações.

Em sintonia com a concepção de ciência, que traz como desafio a superação do paradigma positivista e a emergência da assunção da subjetividade, como fato inerente à composição da realidade estudada, é que optamos pela pesquisa-formação com abordagem multirreferencial que tem como pressuposto central compreender o modo como os sujeitos experimentam e se desenvolvem profissionalmente nas suas experiências, nos diferentes contextos formativos.

A abordagem multirreferencial traz críticas à visão cartesiana baseada na divisão entre espírito e matéria, e a visão positivista, em que o método de observação e experimentação baseia-se apenas nos fatos e suas leis, e pressupõe que o real é palpável, baseado em fatos experimentais. A multirreferencialidade tem como principais pressupostos a pluralidade e a heterogeneidade.

Para Ardoino (1988, p. 24),

a abordagem multirreferencial propõe uma leitura plural de seus objetos (práticos e teóricos), sobre diferentes pontos de vista, que implicam tanto visões específicas quanto linguagens apropriadas às descrições exigidas, em função de sistemas de referência distintos, considerados, reconhecidos explicitamente como não redutíveis uns aos outros, ou seja heterogêneos. 
Percebemos, nessa análise, que a abordagem multirreferencial estabelece um novo olhar sobre o humano, tendo em vista a pluralidade, a partir de novas articulações entre diferentes teorias, desdobrando-se, assim, na edificação de novos conhecimentos sobre os fenômenos sociais, sobretudo os educativos.

A pesquisa-formação tem como base os pressupostos da pesquisa-ação em Barbier (2002) e dos estudos de formação elucidados por teóricos como Shön (2000); Josso (2004); Zeichner (2002); Nóvoa (1995) e Tardif (2004). Em sintonia com esses autores, nos inspiramos nas práticas de educação online desenvolvidas por Santos (2014) e Pereira, (2008).

Nesse contexto, o estudo pressupõe a abordagem biográfica como olhar epistemológica sobre as experiências dos sujeitos sobre sua formação. Para Josso (2004), o trabalho com a narrativa possibilita a passagem de uma tomada de consciência da formação do sujeito para a emergência de um sujeito em formação, possibilitando a reflexão crítica sobre o itinerário experimental e existencial.

Antes dos alunos terem acesso as orientações iniciais sobre a escrita no diário online, trabalhamos a primeira cena do filme "Forrest Gump - o contador de histórias" "com o ator Tom Hanks. A escolha por esse filme se deu por percebermos que através da narrativa de sua vida, o autor foi buscando na sua memória fatos importantes de sua itinerância entrelaçados na história dos Estados Unidos.

Depois da exibição da primeira cena, solicitamos aos alunos algumas reflexões sobre o mesmo e que buscassem no seu baú de memórias aspectos importantes da sua vida pessoal, escolar e universitária. No quadro abaixo, apresentamos algumas orientações iniciais para que o bolsista pudesse iniciar sua escrita.

Filme disponível em: https://www.youtube.com/watch?v=QzHtU2RzpYk Acesso em 20 abril 2016 
Quadro 1 - Sugestões para a elaboração inicial do diário

Algumas sugestões...

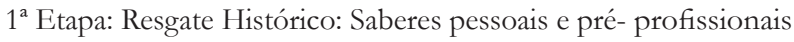

Como era a escola na época em que você estudou? Como você foi alfabetizado?

Relação professor - aluno; Metodologia de trabalho;

Concepção de avaliação;

Todos tinham acesso à escola?

De que forma a escola daquela época contribuía para o exercício da cidadania? Era igual ao que ocorre hoje?

O ensino hoje melhorou ou piorou? Por quê?

É preciso escrever também...

As experiências e modificações na sua sala de aula, a partir do que aprendeu no curso de Pedagogia.

As reações dos alunos às suas mudanças.

Algumas explicações sobre o que aconteceu em sua própria itinerância profissional. As trocas e comentários sobre as experiências de outros professores que estão no curso.

As expressões da criatividade, sentimentos, intuições e percepções sobre seu processo de ensino - aprendizagem.

A importância do outro ( professor, colega, regente, diretor,etc) na sua formação.

Bom trabalho!

Iniciar ou editar a minha anotação no diário

Fonte: Moodle UESB

Após a exibição do vídeo realizam os uma roda de conversa com os bolsistas pedindo que eles narrassem as suas primeiras memórias educativas antes postarem seus relatos no ambiente Moodle. Estas rodas de conversa eram realizadas quinzenalmente e nela as narrativas dos diários eram socializadas para que os colegas, professores supervisores e o professor coordenador pudes- 
se ter acesso a produção, podendo assim agregar sugestões para o aprimoramento do memorial. Os bolsistas aguçaram sua escuta sensível, refazendo suas memórias e posteriormente socializando no diário online da UESB.

Salientamos que na interface diário online do ambiente Moodle, somente o aluno e o docente tem acesso ao diário, que é uma interface um- um. O professor terá o papel de avaliar as reflexões registradas, levantar questionamentos e fazer mediações dos avanços e recuos dos sujeitos envolvidos na atividade. Na nossa pesquisa-formação para o desenvolvimento profissional, que tem como característica principal o choque com a realidade escolar e a emergência de angústias, dilemas, medos e avanços na aprendizagem inicial da docência, essa interface foi de fundamental importância no desenvolvimento do Pibid, configurando-se como um instrumento imprescindível na avaliação formativa.

A medicação individualizada sobre as narrativas desenvolvidas inicialmente sobre as fontes pré-profissionais dos estudantes estão ilustradas nas imagens das figuras 2 e 3.

Salientamos que esse foi um processo intenso de correção, mediação e reflexão junto aos alunos do Pibid, que demonstraram inicialmente muita dificuldade na expressão escrita. A seguir temos duas telas com comentários feitos pela coordenação sobre as escritas nos memoriais, com o objetivo que os bolsista ID agregassem mais reflexões em seus textos, avançando assim na escrita de si.

Figura 2 - Mediação sobre a narrativa do bolsista 1

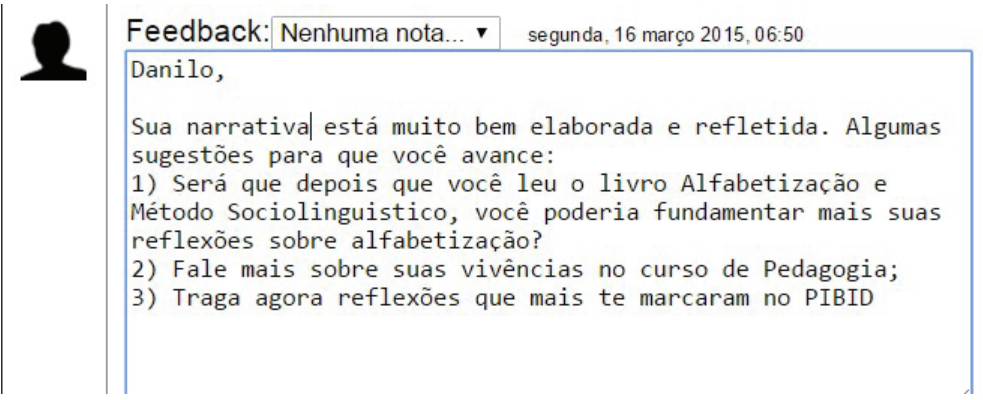

Fonte: Moodle UESB 
Figura 3 Mediação na narrativa do bolsista 2

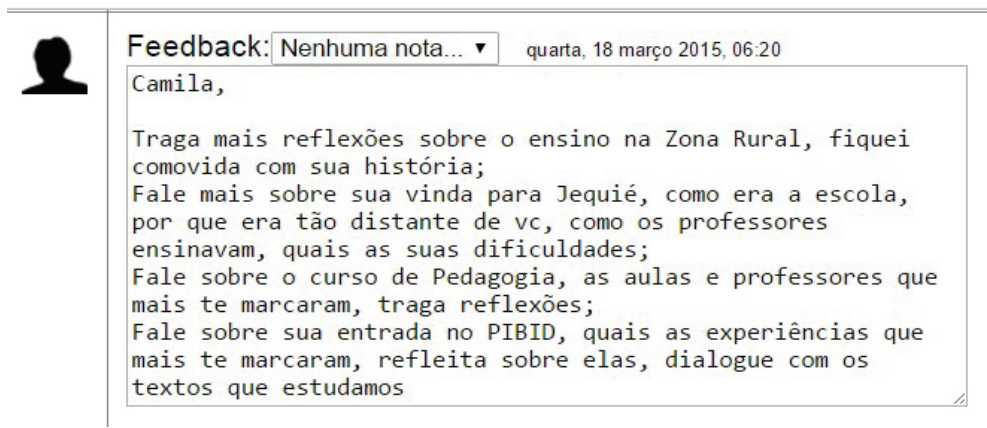

Fonte: Moodle UESB

\section{Resultados e discursos preliminares}

Os desafios explicitados pelo trabalho realizado pelos diários, nos conduziram a uma investigação inspirada nos pressupostos da pesquisa-formação na cibercultura, que traz como fundamento a importância de o pesquisador vivenciar reflexões sobre o processo formativo juntamente com os membros do grupo. Sendo assim, a pesquisa-formação proporcionou aos bolsistas ID e ao pesquisador vivenciarem um movimento constante e contínuo de construção e reconstrução da aprendizagem pessoal e profissional, envolvendo saberes, experiências e práticas.

Em relação aos diários online, destacamos a pluralidade como um dos elementos fundantes nessa abordagem epistemológica, pois o mesmo traz a marca da heterogeneidade como eixo principal na construção do conhecimento. Assim, é preciso romper com perspectivas que tomam como referência a visão homogênea como uma única referência. Esses aspectos foram vivenciados plenamente na socialização dos diários online na nossa pesquisa-formação.

O trabalho com os diários online no Pibid, potencializaram o desenvolvimento profissional dos alunos de iniciação à docência, possibilitando aos mesmos a aquisição de conhecimentos, habilidades e atitudes para enfrentar as problemáticas postas pela prática docente e pelo contexto social mais amplo. Isso nos instigou no 
avanço de propostas de formação que dotassem os profissionais de instrumentos intelectuais para a análise e busca de soluções das questões em que se deparam. Esse desafio foi enfrentado por nós durante os dois anos de trabalho em campo com o Pibid, pois inicialmente os alunos apenas descreviam suas práticas e não traziam reflexões mais aprofundadas sobre as mesmas.

Nossa pesquisa ainda em andamento, tem sinalizado além da importância da reflexão nas narrativas dos bolsistas ID, a relevância da mediação docente, potencializada pela interface comentários, superando uma visão meramente individual da prática pedagógica. Daí a importância do professor como mediador nas situações de ensino, quando produz e orienta diferentes estratégias de aprendizagem necessárias para que os alunos aprendam.

\section{Considerações}

Este texto é parte de uma pesquisa de doutorado, em andamento, desenvolvida junto ao Grupo de Pesquisa em Educação e Culturas Digitais ${ }^{6}$ (Ecult/CNPq/UFS) e por esta razão as considerações aqui apontadas são parciais, uma vez que, nem todos os dados e informações levantadas durante a pesquisa foram devidamente analisados. Entretanto, neste momento, algumas considerações quando as narrativas nos diarios online são possiveis de serem tecidas. A primeira delas é que os diários online são realmente um espaço fecundo de formação, reflexão e discussão das experiências vivenciadas pelos sujeitos envolvidos no processo de aprendizagemensino. Por meio das narrativas nos diários online foi possivel conhecer melhor os bolsiatas ID, sua cultura e suas experiências de vida e formação e desta forma poder mediar as reflexões a cerca das práticas pedagógicos e os dilemas docentes.

Percebemos também que na conteporaneidade para acompanhar e mediar uma formação experiencial como nos indica Macedo (2010) é importante o uso das interfaces, presentes nas tecnolo-

\footnotetext{
${ }^{6}$ Blog do ECult: http:/ /grupoecult.blogspot.com.br/
} 
gias digitais móveis, pelas suas caracteristicas de conectividade, mobilidade e ubiquidade, pois por meio destas tecnologias é possivel explicitar a singularidade e perceber o caráter processual da formação e da vida, articulando espaços, tempos e as diferentes dimensões de nós mesmos, em busca de uma sabedoria de vida e empoderamento do sujeito social contemporâneo.

\section{Referências}

ADORNO, Jaques. Abordagem multirreferencial (plural) das situações educativas e formativas. In: BARBOSA, J. G. (Org). Multirreferencialidade nas ciências e na Educação. São Carlos: EDUFSCar, 1998.

ALVES, Nilda. Decifrando o pergaminho: os cotidianos das escolas nas lógicas das redes cotidianas. In: GARCIA, Alexandra; OLIVEIRA, Inês Barbosa de (Orgs.). Nilda Alves: praticantepensante de cotidianos. Belo Horizonte: Autêntica Editora, 2015.

BARBOSA, Joaquim Gonçalves; HESS, Remi. O diário de pesquisa: O estudante universitário e seu proceso formativo. Brasília: Liber Livro, 2010. BARBIER, René. A pesquisa-ação. Brasília: Plano, 2002.

Centro Regional de Estudos para o Desenvolvimento da Sociedade da Informação (Cetic.br). Pesquisa sobre o Uso das Tecnologias de Informação e Comunicação nos domicílios brasileiros - TIC Domicílios 2016. Disponível em: http://www. cetic.br/pesquisa/domicilios/indicadores. Acesso em 15 abril 2018.

JOSSO, Marie-Christine. Experiências de vida e formação. São Paulo: Cortez, 2004. MACEDO, Roberto Sidnei. Chysallís, currículo e complexidade. A perspectiva crítico- multirreferencial e o currículo contemporâneo. Salvador: EDUFBA, 2002.

MACEDO, Roberto Sidnei. Compreender e mediar a formação: o fundante da educação. Brasília: Liber Livro, 2010.

MORIN, Edgar. Ciência com consciência. 7. ed. rev. mod. Rio de Janeiro: Bertrand Brasil, 2003.

NÓVOA, Antonio (Org.). Os professores e as histórias da sua vida. Portugal: Ed. Porto, 1995. 
PEREIRA, Socorro Aparecida Cabral. Saberes docentes em ambientes virtuais de aprendizagem. Dissertação (Mestrado em Educação). Faculdade de Educação, Universidade Federal da Bahia, Salvador, 2008.

PRETTO, Nelson De Luca. Educações, Culturas e Hackers: escritos e reflexões. Salvador: EDUFBA, 2017.

SANTOS, Edméa. Diário Online: dispositivo multirreferencial de pesquisa-formação na cibercultura. Portugal: WHITIBOOKS, 2014.

SANTAELLA, Lucia. Ecologia pluralista da comunicação: conectividade, mobilidade, ubiquidade. São Paulo: Paulos, 2010.

TARDIF, Maurice. Saberes docentes e formação profissional. Petrópolis: Vozes, 2004. ZEICHNER, Kenneth. Formando professores reflexivos para uma educação centrada no aprendiz: possibilidades e contradições. In: ESTEBAN, Maria Teresa; ZACCUR, Edwiges (Org.). Professora-pesquisadora uma práxis em construção. Rio de Janeiro: DP\&A, 2002.

\section{SOCORRO APARECIDA CABRAL PEREIRA (UESBI)}

Doutoranda em Educação (UFS). Professora do Departamento de Ciências Humanas e Letras da Universidade Estadual do Sudoeste da Bahia. Membro do Grupo de Pesquisa ECult - Educação e Culturas Digitais (UFS/CNPq/Ecult). E-mail: socorrouesb@gmail.com

\section{SIMONE LUCENA (UFS)}

Doutora em Educação. Professora do Departamento de Educação e do Programa de Pós-graduação em Educação da Universidade Federal de Sergipe. Coordenadora de área do Pibid do curso de Pedagogia da UFS Campus Profa. Alberto de Carvalho. Líder do Grupo de Pesquisa ECult - Educação e Culturas Digitais (UFS/CNPq/Ecult). Site: http://grupoecult.blogspot.com.br/ E-mail: slucen@yahoo.com.br 